\title{
Correction to: Mean-based iterative methods for solving nonlinear chemistry problems
}

\author{
Francisco I. Chicharro ${ }^{1}$ (D) Alicia Cordero ${ }^{2}$. Tobías H. Martínez ${ }^{1}$. \\ Juan R. Torregrosa ${ }^{2}$
}

Published online: 5 December 2019

○) Springer Nature Switzerland AG 2019

\section{Correction to: Journal of Mathematical Chemistry https://doi.org/10.1007/s10910-019-01085-2}

The original version of this article unfortunately contained an error in title. Unintentionally, the special issue title was presented in addition to the article's title.

The correct title of the article should read as presented above, "Mean-based iterative methods for solving nonlinear chemistry problems" instead of "CMMSE-2019 mean-based iterative methods for solving nonlinear chemistry problems". This has been corrected by publishing this correction article.

Publisher's Note Springer Nature remains neutral with regard to jurisdictional claims in published maps and institutional affiliations.

The original article can be found online at https://doi.org/10.1007/s10910-019-01085-2.

Francisco I. Chicharro

francisco.chicharro@unir.net

1 Escuela Superior de Ingeniería y Tecnología, Universidad Internacional de La Rioja, Avenida de La Paz, 137, 26006 Logroño, La Rioja, Spain

2 Institute for Multidisciplinary Mathematics, Universitat Politècnica de València, Camino de Vera s/n, 46022 València, Spain 